\title{
Making a Difference with a Discrete Course on Accounting Ethics
}

\begin{abstract}
Calls for the expansion of ethics education in the business and accounting curricula have resulted in a variety of interventions including additional material on ethical cases, the code of conduct, and the development of new courses devoted to ethical development [Lampe, J.: 1996]. The issue of whether ethics should be taught has been addressed by many authors [see for example: Han son, K. O.: 1987; Huss, H. F. and D. M. Patterson: 1993; Jones, T. M.: 1988-1989; Kerr, D. S. and L. M. Smith: 1995; Loeb, S. E.: 1988; McDonald, G. M. and G. D. Donleavy: 1995]. The question addressed in this paper is not whether ethics should be taught but whether accounting students can reason more ethically after an intervention based on a discrete and dedicated course on accounting ethics. The findings in this paper indicate that a discrete intervention emphasising dilemma discussion has a positive and significant effect on students' moral reasoning and development. The data collected from interviews suggest that the salient influences on moral judgement development include: learning theories of ethics particularly Kohlberg's theory of cognitive moral reasoning and development; peer learning; and moral discourse. The implications from the findings in this study suggest that moral reasoning is responsive to particular types of ethics intervention and educators should carefully plan their attempts to foster moral judgement develop ment.
\end{abstract}

KEY WORDS: accounting students, ethics education, ethics interventions, moral discourse, moral reasoning and development, Kohlberg, DIT

\section{Introduction}

During the 1980s the accounting profession suffered a series of setbacks with the financial collapse of business firms whose financial statements received "clean" opinions from their auditors. Critics claim that the audits performed in these cases were not sufficiently reliable to indicate to the recipients of the audited financial information that the firms were experiencing significant financial difficulties (Ash kanasy and Windsor, 1997; Giacomino, 1992; Ponemon, 1995). Two decades later a new wave of corporate scandals erupted: HIH and Harris Scarfe in Australia, Enron and Worldcom in the US, and Parmalat in Europe. Such scandals have again questioned the business and accounting practices of these firms and the role played by their auditors. The implication for auditors is that they are not per forming their tasks to the level expected of profes sional accountants. Yet, the technical competence of professional accountants is rarely questioned, rather, critics claim a breakdown in the ethical standard and behaviour of accountants (Gaa, 1994).

Failed companies such as those listed above fostered a culture of aggressive accounting and are now infa mous for engaging in complex creative accounting practices that deliberately obscure their true financial position and performance. Unfortunately, the collapse of such companies has a domino affect that taints the reputation of the entire profession. In the case of Enron, it led to the demise of Enron's accountants, Arthur Andersen, who subsequently collapsed in their own scandal. The effect on the profession is consid ered by some to be so severe that the profession may be facing a credibility crisis (Earley and Kelly, 2004). Respective governments have responded to the re cent spate of corporate collapses with financial regu latory reforms. However, in addition to such reforms, 
proponents of ethics education are calling for the enrichment ethics in accounting education to restore the credibility of the profession (McPhail, 2001).

Despite claims of increasing ethics education in the business and accounting curricula (Cohen and Pant, 1989; Dellaportas and Leung, 2001; Engle and Elam, 1985; Hoffman and Moore, 1982; Karnes and Sterner, 1988; McNair and Milam, 1993), curricu lum change is evolutionary rather than revolutionary (Pizzolatto and Bevill, 1996). In accounting, ethics is commonly taught in auditing courses, and is often code bound and concerned with rule conformance rather than the underlying ethical issues (Cooke et al., 1987-1988; Kerr and Smith 1995; Langen derfer and Rockness, 1989; Puxty et al., 1994; Wyer, 1987). Therefore, recurring evidence of unethical judgements and fraudulent financial reporting may not be surprising when accounting ethics is not covered in any significant way in most institutions of higher learning (Armstrong and Mintz, 1989; Cohen and Pant, 1989; Cooke et al., 1987-1988). The question addressed in this paper is not whether ethics should be taught but whether such interventions are effective. The purpose of this paper is to deter mine the effect on students' moral reasoning and development from an intervention based on a dis crete course dedicated to accounting ethics educa tion.

The remainder of this paper is structured as fol lows. The next section examines Kohlberg's (1969) theory of cognitive moral reasoning and develop ment (CMD) and empirical evidence in accounting ethics education research. The third section presents the hypothesis, describes the data collection process, the method of data analysis, the accounting ethics course under investigation, and the sample. The fourth section presents the results of the data analysis followed a discussion in the fifth section of the po tential salient factors influencing the results.

\section{Literature review}

\section{Moral reasoning theory and education}

Empirical studies in ethics research are founded on the psychological model developed by Kohlberg (1969), which posits that a person's moral judgement develops over time through a series of six stages, where movement to the next stage is dependent on the person's belief system (see Table I for an outline of the six stages of moral development). Kohlberg's (1969) theory of cognitive moral reasoning and development (CMD) centres on a person's ethical beliefs and how a person's belief system controls the resolution of ethical conflict. According to Kohlberg (1969), "justice" is the criterion that raises one stage of moral reasoning above another with higher stages of moral reasoning offering more equitable solutions to moral dilemmas. Kohlberg's (1969) theory of CMD is extensively addressed in many articles (see for example: Huss and Patterson, 1993; Icerman et al., 1991; Lovell, 1995; Ponemon and Glazer, 1990; Ponemon and Gabhart, 1994) and will not be given undue consideration in this paper. In brief however, the six stages of moral development proceed from self orientated thinking to an abstract principled orientation. Each successive stage of moral development represents a higher level of reasoning regarding the definition and nature of right and wrong and is indicative of a person's ability to reason more ethically. Lower stages of moral reasoning in volve simple concepts of punishment, rewards and relationships with others (family and peers) whereas

TABLE I

The six stages of moral development

\begin{tabular}{llll}
\hline Level & Morality defined & Stage & Orientation \\
\hline Pre conventional & External authority & 1 & Obedience motivated by avoidance of punishment \\
& & 2 & Self gratification \\
Conventional & Social group & 3 & Role expectation and approval from others \\
Post conventional & Inner conscience & 5 & Adherence to legal and moral codes \\
& & 6 & Sust rules determined by consensus \\
\hline
\end{tabular}


higher stages of moral reasoning consider obedience to law and order and complex notions of universal justice.

Kohlberg (1971) argues that most people reason at a single dominant stage and progression to the next stage requires exposure to an environment which stimulates moral reasoning. Empirical research shows that without significant intervention the majority of the adult population will never surpass the middle stages (3 and 4) of Kohlberg's model (Blasi, 1980; Rest, 1986, 1988). Longitudinal research indicates that formal education in post secondary years is a strong and consistent correlate with increasing levels if cognitive moral reasoning (Blasi, 1980; Rest, 1986, 1988; Thoma, 1986). The empirical evidence indicates that moral reasoning develops with increasing levels of formal education. Therefore, education is considered a powerful stimulus for moral judgement development.

Moral education programs (programs designed to promote moral judgement development) as distinct form formal education, have also succeeded in pro ducing substantial gains in moral reasoning (Trevino, 1992). Rest (1986) distinguished four types of interventions: (1) dilemma discussion which engages students in the active problem solving of contro versial moral dilemmas adopting the case study ap proach to education; (2) personality development which involves students in a service project such as cross age tutoring or service at a nursing home; (3) academic programs that emphasise the academic content of humanities, social studies or literature; and (4) short term interventions that are less than 3 weeks regardless of content. Rest (1986) discov ered that dilemma discussion programs are most effective, followed by personality development. The literature suggests that significant gains in moral development do not result from academic courses and short term moral education program interven tions. In summary, moral education programs are effective in promoting moral judgement develop ment, particularly if the program lasts longer than 3 weeks and the intervention involves the partici pants in discussions of controversial moral dilemmas. The process of interactive exchange with students, combined with moral problem solving, appears to speed up the natural development of moral judge ment. The gains do not elevate students' moral development to the levels of moral experts, but the magnitude of change brought about by moral edu cation programs is equivalent to four or five years of natural growth (Rest, 1986, p. 60).

\section{Moral development research in accounting education}

Moral development research in accounting educa tion adopts one of two approaches: the comparative or intervention approach. The comparative ap proach contrasts and evaluates the moral judgement development of accounting students with compara tive groups such as accounting practitioners (Arm strong, 1987); non accounting students (Jeffrey, 1993; St. Pierre et al., 1990); and students from schools with different educational philosophies (Ponemon and Glazer, 1990). In general, the degree of moral development of accountants and account ing students resemble the general population more than it does with groups of comparable educational and occupational status (Armstrong, 1987; Gaa, 1995; Lampe and Finn, 1992; St. Pierre et al., 1990; Ponemon, 1993; Shaub, 1994). This is unfortunate because according to Rest (1986), education is one factor that is shown to have a consistent and positive relationship with moral development that will ele vate them above the general population. Yet the test scores for graduates of accounting degree programs resemble the general population more than the average university graduate.

The intervention approach adopts a pre /post test design to determine changes in moral judgement development test scores, if any, from exposure to ethics education interventions. Ethics interventions in accounting degree programs are generally based on one of two approaches: the "discrete" method which addresses ethical issues in a separate required or optional course, or the "pervasive" method in which ethical issues are integrated into several accounting courses. In accounting education, ethics subject matter is commonly integrated in auditing courses (Armstrong and Mintz, 1989; Cohen and Pant, 1989). Therefore, ethics intervention research in accounting has centred on measuring the effects the pervasive method of ethics intervention at either undergraduate or postgraduate level (e.g., Earley and Kelly, 2004; Lampe, 1996; St. Pierre et al., 1990; Welton et al., 1994). However, ethics interventions in auditing courses do not always have a significant 
effect on post test scores (Earley and Kelly, 2004; Lampe, 1996; Ponemon, 1993). Even when the ef fects of interventions are positive (Welton et al., 1994), follow up studies suggest that the effects are transitory with post test scores reverting to pre test levels (LaGrone et al., 1996). This paper will add to existing knowledge by investigating the effect on accounting students' moral judgement development from the discrete method of intervention rather than the pervasive method.

\section{Research method}

\section{Measuring moral development}

While Kohlberg's primary interest was to devise a theoretical system to represent the logic of moral thinking, Rest (1979) developed the Defining Issues Test (DIT), a valid, objective, reliable measurement instrument of CMD based on the six stages of moral development defined by Kohlberg. The DIT pre sents subjects with moral dilemmas and a number of factors that the subject must consider in resolving each dilemma. The importance given to the "fac tors" emanates in the $\mathrm{P}$ score, "P" standing for "principled morality." A higher DIT P score is indicative of a person's ability to reason at higher stages of moral development according to Kohl berg's framework. A distinct advantage of a con tinuous variable such as the $\mathrm{P}$ score, is the ability to identify changes in moral reasoning by measuring and comparing differences in test scores before and after experimental interventions. Therefore, an in crease in the DIT P score reflects an increased use of principled reasoning (stages 5 and 6) and is arguably evidence of real moral development. The DIT has undergone extensive reliability and validity studies with test and retest reliability for the $\mathrm{P}$ score gen erally in the high 0.70 or $0.80 \mathrm{~s}$ depending on whether the short form (three dilemmas) or long (six dilemmas) form of the DIT is used (Davison and Robbins, 1978). The indices generally fall by about 0.10 points for the three dilemma version of the DIT. However, according to Davison and Robbins (1978) using the shorter three dilemma DIT should have little effect in studies where the mean DIT $\mathrm{P}$ scores are the focus.

\section{Hypothesis and data collection}

Moral judgement development in this study, if any, will be measured by administering the DIT and comparing the mean DIT P scores of accounting students at the beginning and end of a discrete course dedicated to accounting ethics. The three dilemma version of the DIT was issued to students in the first and final weeks of the semester. The treatment phase of the experiment took place during the 12 intervening weeks of the course dedicated to ethics education. The effects of di lemma familiarity from re testing the same subjects with the same dilemmas are negligible. Test-retest studies with an interval of 1-3 weeks, show that the effect on mean $\mathrm{P}$ scores is insignificant (Davi son and Robbins, 1978). However, changes in P scores, if any, beyond the 3 week period are related to the time between the tests and presumably "real" moral development, rather than simply retaking the test. Therefore, Rest (1986) recom mends using the same dilemmas ${ }^{1}$ when imple menting the DIT in a pre / post test design. The change in pre and post DIT P scores in this study will determine whether the discrete method of ethics intervention has an effect on students' moral judgement development. The hypothesis expressed in the null form is thus stated:

$H_{0}$ : The required and dedicated course in accounting ethics will not have a significant effect on DIT P scores.

As discussed above, the statistical correlation between the levels of formal education and increas ing DIT P scores is well established, however, the causal relationship between education and moral judgement development remains conjecture (Rest, 1988; Rest and Deemer, 1986). Therefore, in addi tion to administering the DIT, students were also invited to partake in a semi structured interview. While the test instrument provides a reliable and measurable developmental score, the interviews pro vide a richer analysis on the potential factors that may have affected the way students view and resolve ethical dilemmas. The data collected from interviews will provide a better understanding on the factors that promote moral judgement development in account ing ethics education. 
A formal letter inviting the students to participate in the interviews was issued when the post test instrument was administered. Based on the univer sity ethical guidelines, the researcher obtained in formed consent from the students before they could participate in the interview. Seven students (4 male and 3 female) agreed to be interviewed and the interviews were conducted approximately 2 weeks after the post test was administered. The interviews were recorded on audio tape and later transcribed into electronic word documents. The interviews were principally designed to determine whether the students believed that a dedicated course had a sig nificant effect on the way they analysed and resolved ethical dilemmas. The interviews, on average, lasted around 30 minutes and the discussions, with some latitude to explore unexpected themes, were based around four key questions: Q1. What do you think were the major befits of undertaking a dedicated course in accounting ethics? Q2. Do you believe that your ethical views have changed since undertaking a dedicated course in accounting ethics? Q3. Do you think your responses in the second test instrument changed from completing the first test instrument? Why? Why not? Q4. Do you feel that the change in your responses, if any, can be linked in any way to the dedicated course in accounting ethics?

\section{The course: Ethical issues in accountancy}

The accounting students participating in this study were selected from a large city based Australian university. A feature of the degree program in question is the inclusion of a dedicated and required course in ethics, entitled Ethical Issues in Accoun tancy (EIA). The primary aim of EIA is to sensitise and deepen students understanding of ethical issues in accounting and expose students to ethical theo ries, concepts, values, and rule based frameworks to analyse and resolve ethical dilemmas. Students were introduced to a range of diagnostic tools to aid in the identification and resolution of ethical dilem mas. Exposing students to diagnostic tools enhances their ability to consider the myriad of alternatives and consequences associated with ethical problems from a number of perspectives including; oneself, employer organisations, professional responsibilities, and societal expectations. Students were also ex pected to be conversant with their professional responsibilities by reference to the code of profes sional conduct and the general expectations of the public. An outline of the course content is pre sented in Table II below. In general, the course outline can be divided into two components. Topics 1-7, the first component, provide the conceptual background which underpins students' personal and professional ethical competence. One function of the first component is to provide the diagnostic tools to ethically analyse the issues that commonly face professional accountants. Such is sues are addressed in component 2 of the course outline - Topics 8-12.

While the course was delivered using the con ventional lecture tutorial method of instruction, dilemma discussion and collaborative learning, par ticularly in tutorials, was emphasised in all aspects of the course program. The methods used to generate classroom discussion include the extensive use of hypothetical and real life case studies, formal debating, a business ethics video developed by the Institute of Chartered Accountants in Australia, and a self learning computer program on ethics devel oped by CPA Australia. The course under investi gation in this study emphasised case study analysis and dilemma discussion and therefore by design, is consistent with Rest's (1986) first category of ethics intervention - dilemma discussion.

\section{The sample}

The sample consists of 41 volunteer final year stu dents enrolled in EIA comprising 28 female and 13 male students with a mean age of 22 years. In the pre test procedure, nine students failed the validity checks contained within the DIT leaving 32 valid pre test instruments; and in the post testing, 14 students failed the validity checks (including three instruments that were not submitted) leaving 27 valid post test instruments. The pre and post test instruments were matched for the purpose of paired sampling testing resulting in 26 matched pairs. The matched pairs comprise 20 female students and 6 male students with a mean age 21.94 years. Only 2 of the 26 students are enrolled on a part time basis leaving 24 full time students (see Table III for an outline of the dataset with the respective DIT P scores). 


\section{TABLE II}

Course outline

\section{Topic 1: Introduction}

Relevance and significance of ethics in accountancy

Environmental factors contributing to the significance of ethics in business

Ethics in education: can or should ethics be taught?

Topic 2: Role of professional accountant

Attributes of a profession

The role of the accountant and the profession

Public expectations of accounting professionals and implications for services offered

Sources of ethical guidance: law versus ethics

Topic 3: Factors affecting judgement

Kohlberg's theory of individual moral development

Factors that influence individual decision making and behaviour: stress and time management

Topic 4: Normative theories

Approaches to making ethical and well informed decisions

Consequential versus non consequential ethical theories

Topic 5: Decision models

Attributes of problem solving and decision making

Key features and application of Problem Solving Models

Topic 6: Codes of conduct

Why and how codes of ethics are constructed

The content of professional codes: Fundamental Principles and Standards

Criticisms and review of professional codes

The accounting profession's code of professional conduct

Topic 7: Corporate environment

Corporate codes: purpose focus and content

Effective implementation of the code

Corporate culture and the individual employee and accountants

Topic 8: Conflict of interest

Public interest revisited

Conflict of interest in relation to services offered, improper use of influence and confidentiality

Topic 9: Fraud

Definition \& cost of fraud

Why commit fraud

The role of the internal auditor

Fraud detection \& prevention

Topic 10: Whistle blowing

Definition of a whistle blower

Ethical considerations of whistle blowing

The responsibility of a whistle blower

Reaction to whistle blowers

Tropic 11: Accounting standards

Some practical issues of applying accounting and auditing standards

Ethics and values in the Standard Setting Process

Topic 12: Social responsibility

Describe and discuss the concept of corporate social responsibility and the stakeholder concept

Describe the meaning and provide examples of social and environmental accounting 


\section{Results}

Gender, as a potential factor influencing moral judgement development has been critically exam ined by Gilligan (1977) who argues that male social development is highlighted by a sense of individu ality, while female social development stresses con nectedness between people. According to this view, women recognise responsibilities and respond to perceived obligations that arise from relationships (Reiter, 1996). Gilligan (1982) claims that both males and females are capable of reasoning through relationships and responsibilities, but rarely do males rely on the "care" perspective to justify their deci sions. To this end, women's moral development and ways of reasoning are fundamentally different from those of men. Generally, women's moral reasoning is driven by relationships and obligations to others known as the "ethic of care." Male moral devel opment is driven by the "justice" orientation as defined by Kohlberg. Therefore, according to Gil ligan (1977), Kohlbergian measures (a male defined system) may not accurately measure a female's level of moral development. Consequently, females may appear to be morally inferior to men using Kohl bergian measures.

In spite of Gilligan's concerns, a review of 56 studies examining gender and moral development using DIT $\mathrm{P}$ scores found no significant difference in the levels of moral reasoning levels between males and females (Rest, 1986). In fact differences, when recorded, fa voured females and not males (Rest, 1986; Walker, 1984). Rest (1986) concluded that any variance in test scores attributable to gender was insignificant and, therefore, trivial. In this study, an independent sample $t$ test revealed that the difference in the change be tween the mean pre and post DIT P scores for male and female students $\left(\begin{array}{lll}14.34 & 4.99 & 9.35 \text { percentage }\end{array}\right.$ points - see Table III) is not statistically significant t(26) 2.06, $p \quad 0.38$, two tailed. Consistent with previous DIT evidence, the findings in this study suggest that gender does not have a significant effect on DIT P scores.

Empirical evidence has also demonstrated a strong association between an individual's level of moral development and chronological age (Rest, 1986; Trevino, 1986). According to this view, moral development is a function of maturation resulting from life experiences which change the basic con ceptual structures by which ethical issues are analy sed. The sample under investigation comprises of final year accounting students with the vast majority studying on a full time basis. The majority of the students (15) are aged between 20 and 21 and only three students exceed 25 years. Consequently, the range in ages is quite narrow; therefore, the DIT P scores are not expected to increase significantly with age. A Pearson correlation of the data revealed that age and DIT $\mathrm{P}$ scores are not significantly related $r+0.028, n$ 24, $p \quad 0.445$, one tailed, therefore the DIT $\mathrm{P}$ scores in this study do not increase with age.

The primary purpose of this study is to determine whether a required and dedicated course in accounting ethics makes a difference to students' DIT $\mathrm{P}$ scores. The mean change in pre and post DIT $\mathrm{P}$ scores in this study increased by 12.18 per centage points (38.59 26.41 points, see Table IV) representing a statistically significant post test gain, $t(50) \quad 2.38, p \quad 0.02$, two tailed. ${ }^{2}$ A meta analysis of 55 published and unpublished studies, representing 5,714 subjects and 136 different samples found that the mean DIT P scores increase approximately five percentage points for moral education interventions and 10 percentage points with each progressive level of education: junior high school through to graduate school (Davison and Robbins, 1978; Rest, 1986).

TABLE III

Sample description and DIT P scores

\begin{tabular}{llrcrr}
\hline Variable & & $n$ & Pre DIT P score & Post DIT P score & Change \\
\hline \multirow{2}{*}{ Gender } & Female & 20 & 24.16 & 38.50 & 14.34 \\
& Male & 6 & 33.90 & 38.89 & 4.99 \\
Study mode & Full time & 24 & 26.81 & 37.78 & 10.97 \\
& Part time & 2 & 21.67 & 48.33 & 26.66 \\
\hline
\end{tabular}


The mean increase in DIT P scores in this study (12.18 percentage points) exceeds Rest's (1986) five point average increase for ethics intervention pro grams and it also exceeds the average 10 point in crease for a bachelor degree program. The results in this study are encouraging and suggest that a discrete course in ethics education can make a difference in the way students analyse and resolve ethical dilem mas. Therefore, the null hypothesis is rejected and the results in this study suggest that a required and dedicated course in ethics education has a significant and positive effect on DIT P scores.

\section{Discussion}

Seven students participated in an interview that was designed to elicit the possible salient influences on students' moral judgement development after undertaking a discrete course on accounting ethics. The students raised a variety of issues but common themes emerged. First, the students were generally complimentary of course on accounting ethics and made a number of comments on the impact that ethics education has on the way they analyse and resolve professional and ethical problems. Second, the students highlighted the impact of specific topics taught in EIA, in particular, Kohlberg's theory of CMD. Third, students referred to the teaching methodology that relied predominantly on peer learning and moral discourse. Other less common issues raised in the interviews include the influence of teachers in the learning process and the environment in which the learning occurred. The following discussion draws on these issues as potential causal factors achieving moral judgement development.

\section{TABLE IV}

Mean change in DIT P scores

\begin{tabular}{lcc}
\hline & Mean DIT P score & Standard deviation \\
\hline Post test & 38.59 & 19.67 \\
Pre test score & 26.41 & 17.78 \\
Change & $12.18^{\star}$ & 22.07 \\
\hline
\end{tabular}

$\star_{t}=2.38 ; p=0.02$.

\section{Learning ethics education}

Students were complimentary of undertaking a course in ethics that relied on ethical theories to enhance ethical awareness and sensitivity. For example: "The ability to think analytically when presented with problems has changed the way I view problems and has given me different perspectives to analyse problems." In the case of one student, the ability to consolidate and crystallise existing knowl edge appeared to be a major benefit: "The termi nology and concepts taught in [EIA] has enabled me to pigeonhole what I already know and apply. I have always had these concepts but now I can label them. [EIA] has not changed my personal ethics but has broadened my horizons and realised that there are many more than two alternatives." Although moral change is denied by this student, moral maturation is implied when the student refers to a broadened ethical horizon and a realisation that dilemmas have many equally palatable solutions. Another student, although unsure about his or her ethical actions, emphasised a realisation of enhanced critical think ing: "I don't know whether [EIA] have influenced my actions - it depends on the situation but it has changed the way I think about problems." Other students expressed their views on the conflict reso lution process, for example: "I thought there was always a right and wrong answer, now I believe there may not always be a clear answer;" "There is no one right or wrong path;" and "There is no single answer but other choices." One student went further than mere choice and highlighted the implications of the various alternative courses of action: "In EIA you realise there are choices that affect others."

Not all students were positive about the effects of ethics education. Some students oppose the notion that a one semester course can change the way they resolve ethical problems. For example: "I am strong headed in my beliefs and the concepts in [EIA] will not change the way I think." This remark is con sistent with the view that values are instilled early in life and are unlikely to change as a result of a course on ethics. However, value shaping is only one goal of ethics education, developing ethical awareness and sensitivity even without value shaping is a worthwhile pursuit. As Hanson (1987, p. 4) aptly states: "Ethics education will not convert a "devi ant" to a "virtuous human being" but students with 
good instincts and a genuine concern for others will be able to detect issues more perceptively, to think about them more carefully and to understand more clearly the reasons for acting morally."

\section{Learning Kohlberg's theory of cognitive moral development}

EIA dedicated one of 12 topics (approximately $8 \%$ of the course) to Kohlberg's theory of moral reasoning and development (Topic 3 of course outline) which was intermittently revisited throughout the semester in class discussions. Therefore, CMD was covered as a dedicated session, throughout the course, and as part of the course work. Exposure to Kohlberg's theory coupled with the expectation of formal assessment provides ample motivation for students to learn and understand Kohlberg's moral development framework. Understanding Kohlberg's stages of moral development, in turn, appear to be a potential factor elevating student's moral judgement test scores. In the interviews, students referred to Kohlberg's theory of CMD and indicated how they subsequently give higher priority to Kohlberg's no tions of justice. For example: "Everyone should have a fair go;" and "If I was forced to choose the most important values, depends on the situation really, but fairness comes first." One student ap peared to have internalised Kohlberg's theory to a point where it has affected their way of thinking: "[EIA] has changed the way I think. Kohlberg's theory was very interesting and I now use Kohl berg's theory most of the time to view my prob lems."

However, the DIT was developed presupposing a student is untutored in moral judgement theory. Therefore, administering the post test DIT after exposing students Kohlberg's theory introduces a possible contamination into the post testing (Rest, 1986). Contamination may result because exposure to Kohlberg's stage theory instructs the student on how to perform or make a favourable impression on the DIT. ${ }^{3}$ While students were exposed to Kohl berg's, theory they were not exposed to the DIT or its scoring procedures, therefore, students were uninformed on how to manipulate their responses on the test instrument to achieve a desired result. Rest (1986) concedes that the contamination effect from learning Kohlberg's theory prior to adminis tering the DIT remains unresolved and requires further research. However, Rest (1986) also argues that exposure to Kohlberg's theory should not be viewed as an artificial increase but a true indication of moral judgement development. According to this view, exposure to higher levels of thought is a key ingredient of the developmental process (Reiter, 1996). Learning and understanding the stages of moral reasoning that is higher than one's own stage of development accelerates the moral maturation process. Students learn to adopt and internalise newer and "more ethical or fairer" ways of thinking. Therefore, learning moral development theory should be viewed as a powerful educational tool for changing a person's moral thinking.

\section{Peer-learning and moral discourse}

According to Rest (1986, p. 59), "The active practice in moral problem solving buttressed by interactive exchanges with peers, seems to speed up the natural development of moral judgement." Rest's claims are consistent with Milton Smith (1996) who states that although moral development comes mainly from experience and reflection, it originates in dialogue and instruction. In EIA, the students are presented with a number of case studies for peer led discussion and analysis. To facilitate discussion and meaningful ethical analysis, students were introduced to a variety of analytical tools which include normative ethical theories, profes sional duties and responsibilities, and ethical deci sion making models. According to Armstrong (1993) exposing students to a series of case studies without the tools for theoretical analysis will not enhance the students' ability to reason through them. Therefore, providing students with a theo retical foundation for ethical analysis is critical to facilitate informed moral discourse. Suggested solu tions to cases and tutorial problems were not made available to students at any time throughout the course program. Students' study notes and responses to tutorial work were self developed by relying on tools of ethical analysis provided in the course pro gram and peer discussion in group related activities.

Inherent in ethics interventions based on dilemma discussions are collaborative learning techniques (peer learning), which discuss moral and ethical issues 
with others who are informed about the issues and the ethical theories that may apply to them (Jones, 1988-1989). Students benefit from more active involvement in the learning process (Nelson and Obremski, 1990), particularly when the group lea der's moral development is higher than the group members (Dukerich et al., 1990). The effects from collaborative learning in this study are implied from the interview data. For example, in relation to peer led discussion, one student states: "In [EIA] everyone has ideas that are thrown around that we can all learn from." In some cases, students were influenced by the instructor's contributions to class discussion: ${ }^{4}$ " $[\mathrm{my}]$ answers would change after listening to [the tutor]. [The tutor] had a tendency to demonstrate reality of behaviour by explaining with several examples." Another student states: "[The] tutor shared experiences and I learned from them...I learned it is better to voice concerns rather than keep them in." Irrespective of whether discussion is led by the instructor or one's peers, moral discourse appears to be an effective tool for disrupting one's moral thinking and encouraging moral development. Therefore, students are more likely to demonstrate positive increases in DIT $\mathrm{P}$ scores when they are exposed to different ethical perspectives and moral discourse with as many people as possible, particu larly those with higher levels of moral development.

In spite of the positive results detected in this study, few students were positive about the atmo sphere of the university. For example: "[The uni versity] is a non caring and non supportive university. Lecturers and tutors were generally fine it is the events outside the classroom that made things difficult." In this case, the student was able to dis tinguish teaching and learning issues from extra curricula activities. However, other students were critical of instructors, "staff were distant and I had to rely on my resources and abilities;" and "Some teachers are passive and not approachable and dis couraged me from studying." 5 If these comments are reflective of an environment that is not conducive to moral development, then the findings in this study may have more to do with the student's reflective curiosity rather than the program of learning. In these cases, the student's predisposition to learning, as well as the study of ethics appears to be instru mental to the development of moral reasoning judgement.

\section{Conclusions and implications}

The underlying rationale supporting ethics inter ventions is based on the premise that moral devel opment can be enhanced through the educational process. Empirical research suggests that a purpose fully designed curricula or course intervention can have a positive effect on the development of prin cipled moral judgement during a student's university experience (Pascarella and Terenzini, 1991). In accounting, interventions limited to auditing courses and a pedagogy that emphasises the code of conduct may not be conducive to significant increases in the levels of moral judgement development. However, the findings in this study suggest that an intervention that emphasises "dilemma discussion" within a dedicated course on accounting ethics can have a positive and significant effect on DIT P scores. Specific developmental factors were also explored linking student's moral development with the learning of ethical theories, especially Kohlberg's theory of CMD, peer learning, and moral discourse. The implications of the findings in this paper suggest that moral judgement development is responsive to particular types of ethics intervention. Further re search should target developmental factors in moral judgment development so that educators can care fully plan and focus their educational attempts to foster moral judgement development.

The findings in this study and subsequent gener alisations should be interpreted with caution. The limitations of this study, some of which have been addressed in the body of this paper include, the possibility of a contamination effect by introducing Kohlberg's theory of CMD in the experiment design, the reliance upon a volunteer sample introducing a self selection bias, differences in learning between tutorial groups resulting from different instructors, and a small sample size (26 valid pre and post test instruments and seven interviews) which prevents broad generalisations about the effectiveness of ethics courses. However, rarely has accounting ethics re search examined the effects of a discrete and required course in ethics. Previous research in accounting typically examines the effects of the pervasive method of ethics intervention particularly auditing. There fore, the evidence in this study, which supports the inclusion of a discrete course in accounting ethics, is a positive contribution to existing knowledge and 
provides the starting point for further analysis and discussion on dedicated courses in ethics. Therefore, in spite of the limitations, the post test gains in this study should not be viewed as an artificial increase but a true indication of moral reasoning development and an opening for educators to develop their ethics education programs.

Notwithstanding good intentions, curriculum time in is a scarce resource, therefore, the incorpo ration of a course in ethics in accounting programs is not without opportunity costs (Lampe 1996; Loeb, 1991). The inclusion of ethics into the degree pro gram, particularly a discrete course on ethics, im poses demands on additional resources. For example, producing materials to support a resource based subject takes a great deal of writing and learning time. Staff development and preparation time should not be underestimated and may require special additional funding. Secondly, in order for a curric ulum change to be successful, it must be comple mented with policy development and management support. The introduction of new material invariably means omitting material from more traditional areas of accounting such as financial and management accounting. This may prove difficult when careers, reputations and years of service have been built on understanding, developing and promoting this tra ditional knowledge. Consequently, support for the ethics education wanes in part, from the squeezing out of seemingly important topics for an apparent "softer" topic (Power, 1991). The findings in this study demonstrate, in part, the tangible benefits of ethics education and give evidentiary support for the inclusion of ethics education in accounting pro grams. It is hoped that findings of this, and similar studies, will accelerate the integration of ethics education in accounting programs.

The findings in this study suggest that the "dis crete" method of ethics intervention is a more powerful method of teaching ethics than the "per vasive" method of intervention. However, in teaching ethics, educators should note that a single course in ethics education may be insufficient for a full and proper program of ethics education. Courses dedicated to ethics may not be taught in depth or may be too brief to have a lasting influence on student's ethical sensitivity (Hiltebeitel and Jones, 1991). The success of an ethics program results in part from a sustained discussion in courses by stu dents and staff (Piper et al., 1993). Therefore, stu dents need to be surrounded with opportunities for the discussion and analysis of ethical issues. Ideally, ethics education should be taught as part of a broad based program that includes three elements: (1) an introduction to ethical thought early in the degree program; (2) ethical discussion in existing account ing courses relevant to the topics at hand; and (3) a dedicated capstone course that ties together previous ethics material (Piper et al., 1993; Armstrong, 1993). Each of the three prongs provides distinctive and important benefits that may not be fully achieved if implemented in isolation of each other. Even though a single dedicated course on accounting ethics can have positive effects on students' moral reasoning and development, as discovered in this study, a complete program of ethics education can have more pronounced and lasting effects.

The proposition that moral development is linked to behaviour is a contentious issue that re quires further research and is outside the scope of this paper. However, the issue of ethical behaviour was raised by some students during the interviews and is therefore worthy of a brief note to conclude this paper. The DIT is a measure of one's inten tions not their deeds, therefore, one must not as sume that ethics interventions and increasing DIT $\mathrm{P}$ scores automatically result in improved ethical behaviour (Rest, 1986). Puxty et al. (1994) claim that accountants are induced to act ethically through two aspects of their socialisation, the education process and the influence of their expe riences at work and the role models who show what it means to be ethical. If peers are behaving unethically, previous ethics education may simply be dismissed. Therefore, a successful program of ethics education will not guarantee accompanying changes in behaviour in the workforce (Trevino, 1986). However changes in ethical attitudes, as reflected by changes in DIT P scores may ulti mately have behavioural implications that may re duce the influence of organisational socialisation (Fogarty, 1992). According to one student: "I experienced a workplace problem in [identifying details omitted from this quote], I wish I had done [EIA] then. It would have helped me to approach the problem better." It appears that this student 
may have dealt with the problem more effectively by better understanding the ethical implications of the dilemma, knowing his or her alternative courses of action, being aware of avenues for assistance, and having the courage to stand up for one's convic tions. Changing behaviour, as a course outcome, is difficult, but setting the scene for change is a real istic and an achievable objective that should not be overlooked.

\section{Notes}

1 Rest (1986) has shown that the three dilemmas con sisting of Heinz, Prisoner and Newspaper, have the high est correlation of $\mathrm{P}$ scores, 0.93 of any three dilemma set from the full six dilemma set. The short version of the DIT comprising the dilemmas as recommended by Rest (1986) is utilised in this study.

2 Excluding the two part time students from the sample reduced the mean change in pre and post DIT $\mathrm{P}$ scores from 12.18 to 10.97 percentage points $(26.80-37.77=10.97)$. The paired sample $t$ test, exclud ing the two part time students, found that the mean change in pre and post DIT P scores (10.97 points) was not significant based on the two tailed test: $t(24)=2.01$, $p=0.052$, but was significantly different using the one tail test: $t(24)=1.99, p=0.026$. Therefore, the status of enrol ment appears to have some effect on the results in this study.

3 According to Rest (1988), studies show that it is diffi cult to fake high (upward), but easy to fake low (down ward). McGeorge (1975) conducted a study to test the susceptibility of the DIT to faking and found that subjects could depress their scores by faking low, but could not increase their scores by faking high. This is because sub jects recognise stages they have passed through and can respond appropriately when asked to fake low, whereas stages higher than the subject's own dominant stage level are unknown, thus precluding the ability to fake high.

4 At the time of the data selection, three tutors (includ ing the researcher) were involved in teaching EIA. Regu lar weekly meetings amongst the tutors were held to ensure as far as practicality allows that the approaches to teaching by all three tutors were consistent in all classes. However, it is not unreasonable to expect that personal and situational dynamics could result in differences be tween the tutors and between the classes.

5 In these examples, students were referring to the faculty generally rather than those directly involved in teaching EIA.

\section{References}

Armstrong, M. B.: 1987, 'Moral Development and Account ing Education', Journal of Accounting Education 5, 27-43.

Armstrong, M. B.: 1993, 'Ethics and Professionalism in Accounting Education: A Sample Course', Journal of Accounting Education 11, 77-92.

Armstrong, M.B. and S. Mintz: 1989, 'Ethics Education in Accounting: Present Status and Policy Implications', Association of Government Accountants Journal Summer, 70-76.

Ashkanasy, N. M. and C. A. Windsor: 1997, 'Personal and Organisational Factors Affecting Auditor Indepen dence: Empirical Evidence and Directions for Future Research', Research on Accounting Ethics 3, 35-48.

Blasi, A.: 1980, 'Bridging Moral Cognition and Moral Action: A Critical Review of the Literature', Psycho logical Bulletin 88(1), June, 1-45.

Cohen, J. R. and L. W. Pant: 1989, 'Accounting Edu cators' Perceptions of Ethics in the Curriculum', Issues in Accounting Education 4(1), 70-81.

Cooke, R., H. Kanter and S. Martens: 1987-1988, 'The Importance of Ethical Training in an Accounting Education', The Government Accountants Journal Winter, 64-67.

Davison, M. L. and S. Robbins: 1978, 'The Reliability and Validity of Objective Indices of Moral Develop ment', Applied Psychological Measurement 2(3), Summer, 391-403.

Dellaportas, S. and P. Leung: 2001, 'Ethics Education in the Australian Accounting Curricula', Proceedings of the Accounting Associations of Australia and New Zealand Conference (AAANZ, Auckland).

Dukerich, J. M., M. L. Nichols, D. R. Elm and D. A. Vollrath: 1990, 'Moral Reasoning in Groups: Leaders Make a Difference', Human Relations 43(5), 473-493.

Earley, C. E. and P. Kelly: 2004, 'A Note on Ethics Educational Interventions in an Undergraduate Auditing Course: Is there an Enron Effect?', Issues in Accounting Education 19(1), 53-62.

Engle, T. J. and R. Elam: 1985, 'The Status of Collegiate Auditing Education', Issues in Accounting Education, 97-108.

Fogarty, T. J.: 1992, 'Organizational Socialization in Accounting Firms: A Theoretical Framework and Agenda for Future Research', Accounting, Organizations and Society 17(2), 129-149.

Gaa, J. C.: 1994, The Ethical Foundations of Public Accounting (CGA Canada Research Foundation, Vancouver).

Gaa, J. C.: 1995, 'Moral Judgment and Moral Cognition', Research on Accounting Ethics 1, 253-265.

Giacomino, D. E.: 1992, 'Ethical Perceptions of Accounting Majors and Other Business Majors: An 
Empirical Study', Accounting Educators' Journal 4(2), Fall, 126.

Gilligan, C.: 1977, 'In a Different Voice: Women's Conceptions of the Self and Morality', Harvard Edu cational Review 47, 457-481.

Gilligan, C.: 1982, In a Different Voice (Harvard University Press, Cambridge).

Hanson, K. O.: 1987, 'What Good Are Ethics Courses?' Across the Board September, 10-11.

Hiltebeitel, K. M. and S. K. Jones: 1991, 'Initial Evidence of the Impact of Integrating Ethics into Accounting Education', Issues in Accounting Education 6(2), 262-275.

Hoffman, W. and J. M. Moore: 1982, 'Result of a Business Ethics Curriculum Survey Conducted by the Center for Business Ethics', Journal of Business Ethics 1, 81-83.

Huss, H. F. and D. M. Patterson: 1993, 'Ethics in Accounting: Values Education Without Indoctrina tion', Journal of Business Ethics 12(3), 235-243.

Icerman, R. D., J. N. Karcher and M. Kennelley: 1991, 'A Baseline Assessment of Moral Development: Accounting, Other Business and Nonbusiness Stu dents', Accounting Educators' Journal (Winter), 46-62.

Jeffrey, C.: 1993, 'Ethical Development of Accounting Students, Non Accounting Business Students, and Liberal Arts Students', Issues in Accounting Education 8(1), 87-96Spring.

Jones, T. M.: 1988-1989, 'Ethics Education in Business: Theoretical Considerations', The Organizational Behaviour Teaching Review 13(4), 1-18.

Karnes, A. and J. Sterner: 1988, 'The Role of Ethics in Accounting Education', Accounting Educators' Journal Fall, 18-31.

Kerr, D. S. and L. M. Smith: 1995, 'Importance of and Approaches to Incorporating Ethics into the Account ing Classroom', Journal of Business Ethics 14, 987-995.

Kohlberg, L.: 1969, 'Stage and Sequence: The Cognitive Developmental Approach to Socialization', in D. A. Goslin (ed), Handbook of Socialization Theory and Re search (Rand McNally, New York), pp. 347-480.

Kohlberg, L.: 1971, 'From is to Ought. How to Commit Naturalistic Fallacy and Get Away With it in the Study of Moral Development', in T. Mischel (ed), Cognitive Development and Epistemology (Academic Press, New York), pp. 151-235.

LaGrone, R. M., R. E. Welton and J. R. Davis: 1996, 'Are the Effects of Accounting Ethics Interventions Transitory or Persistent?', Journal of Accounting Education 14(3), 259-276.

Lampe, J. C. and D. W. Finn: 1992, 'A Model of Auditors' Ethical Decision Processes', Auditing: A Journal of Practice \& Theory 11, Supplement, 33-59.
Lampe, J.: 1996, 'The Impact of Ethics in Accounting Curricula', Research on Accounting Ethics 2, 187-220.

Langenderfer, H. Q. and J. W. Rockness: 1989, 'Inte grating Ethics into the Accounting Curriculum: Issues, Problems, and Solutions', Issues in Accounting Education 4(1), Spring, 58-69.

Loeb, S. E.: 1988, 'Teaching Students Accounting Ethics: Some Crucial Issues', Issues In Accounting Education Fall, 316-329.

Loeb, S. E.: 1991, "The Evaluation of "Outcomes" of Accounting Ethics Education', Journal of Business Ethics 10, 77-84.

Lovell, A.: 1995, 'Moral Reasoning and Moral Atmo sphere in the Domain of Accounting', Accounting, Auditing and Accountability Journal 8(3), 60-80.

McDonald, G. M. and G. D. Donleavey: 1995, 'Objec tions to the Teaching of Business Ethics', Journal of Business Ethics 14(10), 839-853.

McGeorge, C.: 1975, 'Susceptibility to Faking of the Defining Issues Test of Moral Development', Devel opmental Psychology 11(1), 108.

McNair, F. and E. E. Milam: 1993, 'Ethics in Accounting Education: What is Really Being Done', Journal of Business Ethics 12((10), October, 797-807.

McPhail, K.: 2001, 'The Other Objective of Ethics Education: Re humanising the Accounting Profession - A Study of Ethics Education in Law, Engineering, Medicine and Accountancy', Journal of Business Ethics 31(3/4), 279-299.

Milton Smith, J.: 1996, 'Forces for Cultural Change: The Findings of The Australian Business Ethics Project', in K. Woldring (ed.), Business Ethics in Australia and New Zealand Essays and Cases (Thomas Nelson Australia, South Melbourne), pp. 273-287.

Nelson, D. R. and T. E. Obremski: 1990, 'Promoting Moral Growth Through Intra Group Participation', Journal of Business Ethics 9(9), 731-739.

Pascarella, E. T. and P. T. Terenzini: 1991, How Uni versity Affects Students (Jossey Blass Publishers, San Francisco).

Piper, T. R., M. C. Gentile and S. D. Parks: 1993, Can Ethics Be Taught? Perspectives, Challenges, and Approaches at Harvard Business School (Harvard Business School, Boston, Massachusetts).

Pizzolatto, A. B. and S. Bevill: 1996, 'Business Ethics: A Classroom Priority?', Journal of Business Ethics 15, 153158.

Ponemon, L. A.: 1993, 'The Influence of Ethical Rea soning on Auditors' Perceptions of Management's Competence and Integrity', Advances in Accounting 11, $1-29$. 
Ponemon, L. A.: 1995, 'The Objectivity of Accountants' Litigation Support Judgements', The Accounting Review 70(3), 467-488.

Ponemon, L. A. and D. R. L. Gabhart: 1994, 'Ethical Reasoning Research in the Accounting and Auditing Professions', in J. R. Rest and D. Narvaez (eds), Moral Development in the Professions: Psychology and Applied Ethics (Lawrence Erlbaum Associates Publishers, Hillsdale, New Jersey), pp. 101-119.

Ponemon, L. A. and A. Glazer: 1990, 'Accounting Education and Ethical Development: The Influence of Liberal Learning on Students and Alumni in Accounting Practice', Issues in Accounting Education 5(2), Fall, 195-208.

Power, M. K.: 1991, 'Educating Accountants: Towards a Critical Ethnography', Accounting, Organizations and Society 16(4), 333-353.

Puxty, A., P. Sikka and H. Willmott: 1994, '(Re)forming the Circle: Education, Ethics and Accountancy Prac tices', Accounting Education 3(1), 77-92.

Reiter, S. A.: 1996, 'The Kohlberg-Gilligan Contro versy: Lessons for Accounting Ethics Education', Critical Perspectives on Accounting 7, 33-54.

Rest, J. R.: 1979, Revised Manual for The Defining Issues Test (University of Minnesota, Minneapolis).

Rest, J. R.: 1986, Moral Development: Advances in Research and Theory (Praeger, New York).

Rest, J. R.: 1988, 'Why Does University Promote Development in Moral Judgement?', Journal of Moral Education 17(3), October, 183-194.

Rest, J. R. and D. Deemer: 1986, 'Life Experiences and Developmental Pathways', in J. R. Rest (ed), Moral Development: Advances in Research and Theory (Praeger, New York), pp. 28-58.

Shaub, M. K.: 1994, 'An Analysis of the Association of Traditional Demographic Variables With the Moral
Reasoning of Auditing Students and Auditors', Journal of Accounting Education 12(1), 1-26.

St. Pierre, K. E., E. S. Nelson and A. L. Gabbin: 1990, 'A Study of the Ethical Development of Accounting Majors in Relation to Other Business and Nonbusiness Disciplines', The Accounting Educators' Journal, 23-35.

Thoma, S. J.: 1986, 'Estimating Gender Differences in the Comprehension and Preference of Moral Issues', Developmental Review 6, 165-180.

Trevino, L. K.: 1986, 'Ethical Decision Making in Or ganisations: A Person Situation Interactionist Model', Academy of Management Review 11, 601-617.

Trevino, L. K.: 1992, 'Moral Reasoning and Business Ethics: Implications for Research, Education, and Management', Journal of Business Ethics 11, 445-459.

Walker, L.: 1984, 'Sex Differences in the Development of Moral Reasoning: A Critical Review', Child Develop ment 55, 677-691.

Welton, R. E., M. LaGrone and J. R. Davis: 1994, 'Promoting the Moral Development of Accounting Graduate Students: An Instructional Design and Assessment', Accounting Education 3(1), 35-50.

Wyer, J. C.: 1987, Report of the National Commission on Fraudulent Financial Reporting: The Potential for Educa tional Impact (Report of the National Commission on Fraudulent Financial Reporting).

Steven Dellaportas School of Business, University of Ballarat, 6633353, Victoria, Australia E-mail:s.dellaportas@ballarat.edu.au 